Stakeholder perceptions on governance for the protection and increase of forest cover in the Panama Canal Watershed

Daniella Schweizer

University of California, Environmental Studies Department. 1156 High Street. Santa Cruz, CA. 95064.

Email: daniellaschweizer@gmail.com

Current address: São Paulo University, Agriculture School Luiz de Queiroz, Piracicaba, São Paulo, Brazil.

(C) 2017. This manuscript version is made available under the Elsevier user license http://www.elsevier.com/open-access/userlicense/1.0/ 


\title{
Stakeholder perceptions on governance for the protection and increase of forest cover in the Panama Canal Watershed
}

\author{
Abstract \\ Governance regimes have been endorsed by governments, academics and \\ developmental aid agencies as a way to achieve complex environmental and social \\ objectives. The Integrated Watershed Management governance regime for the \\ Panama Canal's Watershed was formed to achieve the protection and restoration of \\ forest cover. I assessed through semi-structured and open ended interviews the \\ perceptions of government and community stakeholders on the achievements and \\ challenges of the regime. The main achievements include increased environmental \\ awareness of the community members and their empowerment to lead meetings with \\ local authorities and hold them accountable for provision of solutions to social and \\ environmental issues. Long-term sustainability of the governance structure is \\ challenged by discrepancies between the desire of community members to be \\ recipients of funds to conduct environmental projects and the vision of the \\ government institution, the Panama Canal Authority that wants voluntary participation \\ of the community. Lack of support from other government institutions limits the \\ impact of the governance regime for providing social and environmental solutions. The \\ governance regime can profit from greater communication between actors and a \\ greater allocation of responsibilities to local community organizations.
}

\section{Introduction}

Countries all around the world have come to acknowledge the pressing need of restoring and protecting forests as they provide several key services needed for human well-being and climate change mitigation. That acknowledgment led to global commitments to increase forest cover such as the Aichi Target $\mathrm{N}^{\circ} 15$ of the Convention for Biological Diversity, aimed at restoring $15 \%$ of degraded ecosystems, and the Bonn Challenge to restore 150.000 .000 ha by 2020 . Global commitments must be accompanied by innovative governance regimes for the implementation of landscape restoration and environmentally sound land use management.

Proponents of environmental governance regimes claim that through "the recognition that no single agent possesses the necessary capabilities to address the multiple facets, scales and interdependencies of environmental problems... environmental governance can produce positive social as well as ecological outcomes" (Agrawal and Lemos 2007: 39). Whereas skeptics caution against idealizing such regimes due to the potential for increased privatization of natural resources, fear of greater inequality, lack of true changes in power dynamics and concerns of potential paralysis or slowness in the drafting of necessary and urgent environmental policy reforms. Therefore, it becomes important to critically evaluate established environmental governance regimes.

The Integrated Watershed Management Plan of the Panama Canal Watershed (IWNP) is an interesting government led initiative to protect and restore forest cover in the Panama Canal Watershed through the participation of several stakeholder groups. The 
present case study gathers the perceptions of government and community stakeholders on the achievements and challenges of the regime.

\section{Forest governance in the Panama Canal Watershed}

The Panama Canal Watershed is an important feature of the global landscape, since it provides the water for a key component of the World's economy: the Panama Canal. The Canal connects the Pacific and Atlantic Oceans via Gatun Lake, an artificial freshwater lake, which is fed by several rivers in the watershed. Water usage increases, due to the recent expansion of the Canal, plus continued deforestation and climate change made forest cover conservation and restoration in the watershed a priority of the government.

A single government institution, the Panama Canal Authority (ACP), is responsible for overseeing the functioning of the Canal and guaranteeing continuous water supply via the conservation of critical areas. To achieve its mandate, while meeting the needs of the local communities, the ACP adopted a governance regime to managing the watershed: the Integrated Watershed Management Regime. To this end, the ACP created the Interinstitutional Commission for the Panama Canal Watershed ( $\mathrm{CICH})$. The $\mathrm{ClCH}$ is a multi-scale governance regime, with community based watershed committees representing the local scale. Three community members hold the main managerial positions of president, secretary and treasury for one year, with the possibility of re-election. Watershed committees meet on a monthly basis to discuss environmental issues, projects in the area, fund raising activities, and plan which issues they will communicate to local government authorities. The consultative councils, which gather community organizations from several sub-watersheds and local officials conforms the regional scale. The Secretary Executive of the $\mathrm{ClCH}$ and the Interinstitutional Commission compose the national scale in which government officials from the different ministries participate (Fig. 1).

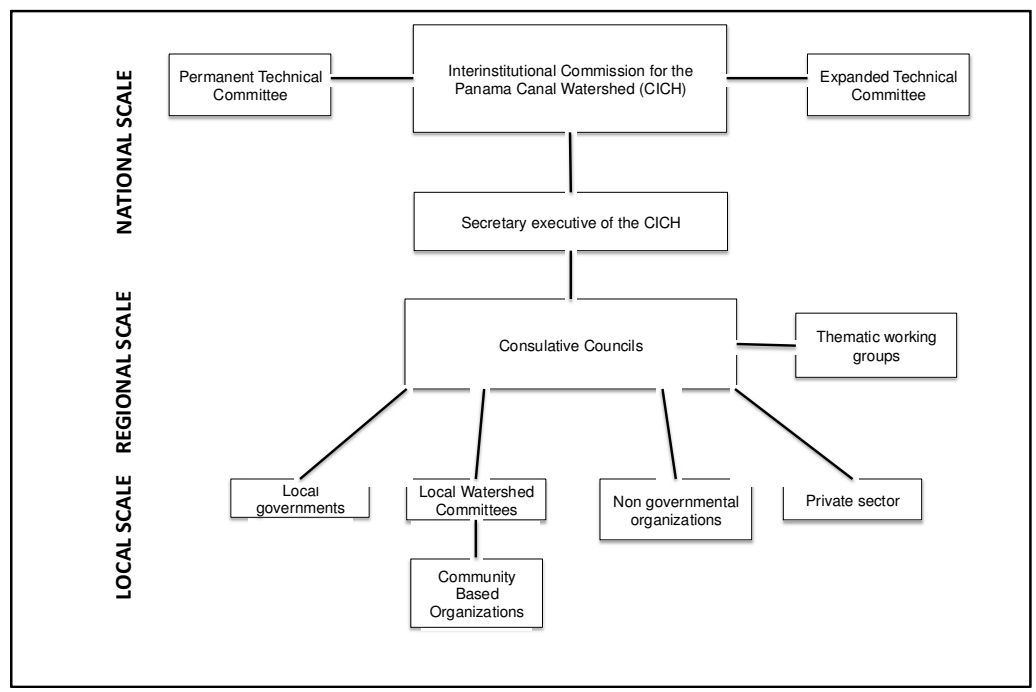

Figure 1. Structure of the Integrated Watershed Management Regime

The consultative councils were established based on social and cultural criteria, similar socio-economic profiles, proximity to protected areas, and access to basic services. 
This resulted in five councils, which bring together six or more watershed committees with their local government officials. Non-governmental organizations and members of the private sector can participate in these councils. The basis for the work at the level of the consultative councils are the Management and Action plans for watershed management drafted by the watershed committees during environmental assessments and prioritization exercises conducted with the ACP. The councils meet every three months, but there are permanent working groups organized around specific thematic areas (e.g. environment). Three elected members from the watershed committees hold the main managerial positions at the council for one year without possibilities for re-election.

\section{Stakeholder perceptions on governance of the Panama Canal Watershed}

Stakeholder perceptions on the performance of the IWMP were collected thru semistructured interviews conducted in 2010 in two sub-watersheds of Panama Canal Watershed: Chilibre and Chilibrillo, in the Eastern side of the Canal, and Trinidad and Ciri Grande in the Western side. These two areas differ from each other in the socioeconomic profile of the communities. Chilibre and Chilibrillo lie on the main road between Panama City and Colón and are characterized by poor urban neighborhoods. Trinidad and Ciri Grande, are surrounded by cattle ranching, shifting agriculture, commercial coffee, palm-heart, pineapple, and poultry operations. In addition, key informant, open-ended interviews were conducted with active members from the watershed committees and ACP's staff members. I coded and grouped qualitative responses based on the following categories: respondent membership to community based organizations, perspectives about the watershed and the community, awareness of the importance of forest cover, and overall environmental awareness. I further grouped these according to perceived achievements and challenges of the governance regime.

The stakeholders interviewed perceive one of the main achievements of the IWMP relates to an increase in people's environmental awareness and empowerment of local communities to discuss social and environmental problems with local authorities. Over 60 percent of the interviewees related watershed conservation with the protection of water sources and forest cover and were aware that environmental quality in the watershed diminished thru time.

The ACP focus for implementation of the IWMP has been the capacitation of communities mainly via environmental education. The ACP believes a key aspect in the adequate functioning and long-term sustainability of this governance regime lies "in the recognition, by community members, of the importance of this process and of environmental problems in the Watershed" ( $\mathrm{ClCH}$ secretary). Capacity building is a key component of the narrative of decentralized governance because it empowers people to become active participants in local socio-political and environmental decisions and it focuses more on changing environmental attitudes through education and less on changing behavior based on economic incentives (Lemos and Agrawal 2006). Communities' active participation in raising socio-environmental concerns to local authorities was accomplished by the cross-scalar nature of the governance structure in place, where the local scale engages with the regional scale in the consultative 
councils. Community members lead the councils while government officials and ACP staff present advancements of projects.

Despite advances in communities involvement with local authorities. Community members identified the lack of projects as a major challenge for long term sustainability of the governance regime: "We have been almost 8 years in this process and still not a single project has come to us, that is frustrating... We receive hundreds of capacitation workshops, but then our knowledge is not employed in the execution of projects" (Eastern Watershed Committee member). This challenge was stronger in the urban communities on the eastern part of the watershed, which had also been challenged by a small membership perceived to be due to lack of peoples free time. The watershed committees in the rural western portion of the watershed had been active for six years without interruption, had one-year old consultative councils and were discussing their participation in at least two different environmental projects.

Community members in the urban portion wanted to be recipients of funds to conduct projects, however, that contradicted the mission of the ACP for the committees:

"... local watershed committees cannot execute projects... they are supposed to be the link between the established Community Based Organizations and the institutions. If they execute projects they lose their identity and become another Community Based Organization" (Director of ACPs social actions department). Haenn (2005) working in an indigenous area in Mexico observed that people engaged in projects brought by development agents with the idea of acquiring paid positions. After a strong protest, peasants in her area of work demanded that government funds be channeled through "campesino organizations". These types of disputes indicate that fundamental rearrangements of political structures are needed that clearly establish who is in control, who sets agendas, who allocates resources and who mediates disputes. It becomes important to establish an open dialogue between communities and the APC that can allow working towards a solution of discrepancies to avoid conflict.

The relationship observed between socio-economic level and political dynamics in the Panama Canal Watershed is summarized well by the following quote:

"Communities that are in the transition from being rural to being peri-urban, but are experiencing this in a context of marginalization, are very difficult to sensibilize towards protecting the natural resources without talking about an increase in their quality of life...In rural areas people tend to have a higher cohesiveness than in urban settings. $A$ low immigration rate in rural areas means people know each other more. The lack of many services and institution support in rural areas mean that community members maintain alive the initiative of being their own agents of solving issues" (ACP staff member).

Despite the intention of decentralization the Integrated Watershed Regime represents, the lack of decision-making power in the local branches of government shows a great degree of centralization of public economic resources: "The ACP was given as a constitutional mandate the immense task of conserving the water resource in the Panama Canal Watershed... but was not given the power to draft regulations, laws or other instruments to execute the mandate ... Until the State assumes the conservation 
of the Panama Canal Watershed as a matter of State, the actions by the ACP will be very weak and challenged" (ACP staff member).

A situation referred to as the "challenge of plurality" (Cash et al. 2006) where the perspectives and agendas of all relevant actors, at the central and local levels must be accommodated but the central government still tries to maintain control. Unfortunately, multi-stakeholder governance arrangements do not resolve interinstitutional conflicts over power, mandates, and responsibilities (Haenn 2005). Getting support from other government branches in the governance process is key for the ACP as most actions to execute the watershed management plan lie in the hands of other government institutions.

\section{Lessons learned}

The establishment of a governance regime for the protection and recovery of forest cover in the Panama Canal Watershed is perceived by stakeholders as positive in that community members now have access to local authorities and feel empowered in bringing up socio-environmental concerns to them. This is important as community engagement with local authorities is key to effective decentralization of environmental governance (Wright et al 2016). Nevertheless, presence of the government is still needed for the sustainability of the governance structure signaling a strong top-down approach with little involvement of communities in projects. The established governance structure has yet to show increased decision-making power in the communities. In addition, solutions to socio-ecological issues will require stronger commitment from the different government institutions acting in the watershed. Despite the challenges perceived, I believe this governance structure is a step in the right direction concerning forest cover protection and reforestation as is providing communities with increased environmental sensibility and access to authorities .

\section{Acknowledgements}

I would like to thank the logistical support provided by the Panama Canal Authority for the conduction of this work. Funding from the Smithsonian Tropical Research Institution as well as facilities for accommodation while conducting the work where fundamental for the research.

\section{References}

Agrawal, A and MC Lemos. (2007). A greener revolution in the making? Environmental governance in the 21st century. Environment 49:36-49.

Cash, DW, WN Adger, F Berkes, P Garden, L Lebel, P Olsson, L Pritchard, and O Young. 2006. Scale and cross-scale dynamics: Governance and information in a multilevel world. Ecology and Society 11: 8.

Haenn, N.2005. Fields of power, forests of discontent. The University of Arizona Press, Tucson. $229 \mathrm{pp}$.

Lemos, MC and A Agrawal. 2006. Environmental Governance. Annual Review of Environmental Resources 31:297-325.

Wright, G., K.P. Andersson, C.C. Gibson and T.P. Evans. 2016. Decentralization can help reduce deforestation when user groups engage with local government. Proceedings of the National Academy of Sciences 52: 14958-14963. 